\title{
¿Puede el sabor de un alimento ser considerado una obra PROTEGIDA POR EL DERECHO DE AUTOR? COMENTARIO DE LA SENTENCIA No C $310 / 17$ dEL TRIBUNAL dE JUSTICIA DE LA UNIÓN EUROPEA, GRAN SALA, 13 dE NOVIEMBRE DE 2018*
}

Michelle Azuaje Pirela

Trabajo recibido el 16 de noviembre de 2018 y aprobado el 03 de diciembre de 2018

\section{Planteamiento}

En las siguientes páginas se presenta el análisis de la sentencia dictada por el Tribunal de Justicia de la Unión Europea en fecha 13 de noviembre de 2018, con motivo del asunto C310/17, que tiene por objeto la resolución de una petición de decisión prejudicial planteada, con arreglo al artículo 267 Tratado de Funcionamiento de la Unión Europea,' por el gerechtshof Arnhem-Leeuwarden (Tribunal de Apelación de Arnhem-Leuvarda, Países Bajos).

Trabajo recibido el 28 de diciembre de 2017 y aprobado el 26 de septiembre de 2018

En ella la Gran Sala realiza la interpretación de los elementos que integran el concepto de "obra", a efectos de la Directiva 2001/29/CE², relativa a la armonización de determinados aspectos de los derechos de autor y derechos afines a los derechos de autor en la sociedad de la información.

Así, en el marco de un litigio entre Levola Hengelo BV (en lo sucesivo, "Levola") y Smilde Foods BV (en lo sucesivo, "Smilde"), se determina si es posible considerar "el sabor de un alimento" como una obra protegida por el derecho de autor, y, en consecuencia, si se infringieron los derechos de propiedad intelectual de Levola en relación con dicho bien inmaterial.

\section{SínteSis de LA CONTROVERSiA}

En el año 2007 un comerciante neerlandés creó el "Heksenkaas" o "Heks'nkaas" (en lo sucesivo, "Heksenkaas") un queso para untar con nata fresca, finas hierbas y verduras. En el año 2011, a través de un contrato, el creador de este producto cedió a Levola sus derechos de propiedad intelectual, acordando como contraprestación una remuneración en función del volumen de ventas. El 10 de julio de 2012 se concedió una patente por el método de producción del Heksenkaas.

Desde enero de 2014, Smilde fabrica un producto denominado "Witte Wievenkaas" para una cadena de supermercados en los Países Bajos. En ese sentido, al considerar que la producción y venta del Witte Wievenkaas infringía sus derechos de autor sobre el "sabor" del Heksenkaas, Levola presentó una demanda contra Smilde ante el rechtbank Gelderland (Tribunal de Primera Instancia de Güeldres, Países Bajos).

1 Versión Consolidada. Diario Oficial de la Unión Europea, 30 de marzo de 2010.

2 del Parlamento Europeo y del Consejo, de 22 de mayo de 2001.

Michelle Azuaje Pirela, Profesora de Derecho Civil, Universidad Autónoma de Chile. Corresponsal de la Asociación para el estudio y la enseñanza del Derecho de Autor "ASEDA". Correo electrónico: michelle.azuaje@uautonoma.cl. 
La pretensión de Levola se basa fundamentalmente en que se reconozca y defienda su derecho de autor sobre el sabor de su obra. El elemento central de la misma radica en que, a su decir, el derecho de autor sobre un sabor remite a la "impresión de conjunto producida por el consumo de un alimento en los órganos sensoriales del gusto, incluida la sensación bucal percibida a través del tacto."

Para el demandante el sabor de un alimento puede calificarse de obra literaria, científica o artística protegida por los derechos de autor, lo que intenta justificar citando la sentencia de 16 de junio de 2006 del H.R. der Nederlanden (Tribunal Supremo de los Países Bajos)³', Lancôme, en la que este último órgano jurisdiccional admitió, en principio, la posibilidad de reconocer un derecho de autor sobre el olor de un perfume. ${ }^{4}$

Por ello invocando la analogía, solicitó al Tribunal de Primera Instancia de Güeldres que declarase, por una parte, que el sabor del Heksenkaas es una creación intelectual que pertenece a su fabricante y que, por lo tanto, disfruta, como obra, de la protección del derecho de autor, con arreglo al artículo 1 de la Ley sobre el Derecho de Autor neerlandesa, y, por otra parte, que el sabor del producto fabricado por Smilde es una reproducción de dicha obra realizada sin su autorización y por tanto, infractora de sus derechos.

De esta forma se requirió al mismo órgano jurisdiccional que ordenase a Smilde el cese de cualesquiera infracciones de su derecho de autor, incluida la producción, compra, venta y cualquier otra comercialización del producto denominado "Witte Wievenkaas."

Por su parte, para la demandada la protección de los sabores no se ajusta al régimen de los derechos de autor, que comprende únicamente las creaciones visuales y auditivas. Asimismo, opina que la inestabilidad de un alimento y el carácter subjetivo de la percepción gustativa impiden considerar el sabor de un alimento como una obra protegida por los derechos de autor. En consecuencia, los derechos exclusivos del autor de una obra de propiedad intelectual y las limitaciones a las que están sometidos esos derechos, en la práctica, son inaplicables a los sabores.

A este respecto mediante sentencia de 10 de junio de 2015, el Tribunal de Primera Instancia de Güeldres consideró que, sin que fuera necesario pronunciarse sobre la cuestión de si el sabor del Heksenkaas podía ser protegido con arreglo al derecho de autor, las pretensiones de Levola debían desestimarse en cualquier caso, ya que esta empresa no había indicado los elementos o la combinación de elementos del sabor del Heksenkaas que le daban un carácter propio y original y una impronta peculiar para que pudiese en todo caso ser considerado una obra.

Levola interpuso recurso de apelación contra dicha sentencia. El Tribunal de alzada consideró que la cuestión central planteada en el asunto principal es si el sabor de un alimento puede estar protegido por los derechos de autor. La apelación corresponde decidirla al gerechtshof Arnhem-Leeuwarden (Tribunal de Apelación de Arnhem-Leuvarda, Países Bajos), que es el tribunal remitente de la cuestión prejudicial en comento, quien señala que la Cour de cassation (Tribunal de Casación, Francia) ha desestimado categóricamente, en particular, en su sentencia de 10 de diciembre de $2013^{5}$, la posibilidad de que la protección de los derechos de autor se extienda a un olor.

\footnotetext{
3 HR, 16 de junio de 2006, LJN AU8940, Kecofa/Lancôme.

4 Al respecto puede consultarse a Koelman (2006), quien explica que en este caso el Tribunal Supremo de los Países Bajos dictaminó que la fragancia de un perfume puede, en principio, ser objeto de protección mediante el derecho de autor. En ese sentido se estableció que el olor de un perfume puede cumplir los criterios de expresión y originalidad, pese a que sólo pueda percibirse a través del olfato. El Tribunal distinguió entre la fragancia de un perfume y su fórmula y el líquido que la contiene, comparando este último con el papel de las páginas de un libro, que no es materia de protección por derecho de autor, en tanto que el contenido del libro sí que lo es. Esta diferenciación significa que la elaboración de un perfume a partir de ingredientes completamente distintos pero que transmite la misma fragancia que otro perfume puede constituir una infracción, en tanto que no sería el caso de dos perfumes con formulaciones similares, pero con fragancias diferentes.

5 Cour de cassation, chambre commerciale, 10 de diciembre de 2016, № 11-19.872 (ECLI:FR:CCASS:2013:CO01205).
}

AZUAJE PIRELA, Michelle. ¿Puede el sabor de un alimento ser considerado una obra protegida por el derecho de autor? Comentario de la sentencia n c 310/17 del Tribunal de Justicia de la Unión Europea, gran sala, 13 de noviembre de 2018. Revista Justicia y Derecho, Santiago, v. 1, no 1, 2018 
En consecuencia, la jurisprudencia de los tribunales supremos nacionales en la Unión Europea ha discrepado en lo que respecta a la cuestión de si un olor queda protegido por el derecho de autor, no quedando claro entonces si puede aplicarse la analogía invocada por el demandante. Por esa razón el Tribunal de Apelación decidió suspender el procedimiento y plantear al Tribunal de Justicia de la Unión Europea las siguientes cuestiones prejudiciales:

1) ¿Se opone el Derecho de la Unión a que el sabor de un alimento, como creación intelectual propia de su autor, quede protegido por el derecho de autor? En particular:

a) ¿Se opone a la protección por el derecho de autor el hecho de que el concepto de "obras literarias y artísticas" contenido en el artículo 2, apartado 1, del Convenio de Berna, que es vinculante para todos los Estados miembros de la Unión, comprenda "todas las producciones en el campo literario, científico y artístico, cualquiera que sea el modo o forma de expresión", cuando los ejemplos citados en dicha disposición solo hacen referencia a creaciones que pueden percibirse visualmente o de manera auditiva?

b) ¿Se opone la inestabilidad (potencial) de un alimento o el carácter subjetivo de la percepción gustativa a que el sabor de un alimento tenga la consideración de obra protegida por el derecho de autor?

c) ¿Se opone el régimen de derechos exclusivos y excepciones, establecido en los artículos 2 a 5 de la Directiva 2001/29/CE, a que el sabor de un alimento esté protegido por el derecho de autor?

2) En caso de respuesta negativa a la cuestión 1 a):

a) ¿Qué requisitos deben cumplirse para poder proteger el sabor de un alimento mediante el derecho de autor?

b) ¿Se refiere la protección de un sabor mediante el derecho de autor únicamente al sabor como tal o (también) a la receta del alimento de que se trate?

c) ¿Qué debe alegar la parte que, en el marco de un procedimiento (de infracción), afirma haber creado el sabor de un alimento protegido por el derecho de autor? ¿Resulta suficiente que, durante dicho procedimiento, dicha parte presente el alimento al juez nacional para que el propio juez aprecie, tras olerlo y probarlo, si el sabor del alimento cumple los requisitos para obtener la protección del derecho de autor? ¿O debe la parte demandante facilitar (también) una descripción de las decisiones creativas adoptadas en el marco de la composición del sabor o de la receta que permitan considerar que el sabor constituye una creación intelectual propia de su autor?

d) En el marco de un procedimiento por infracción, ¿cómo debe constatar el juez nacional si el sabor del alimento correspondiente a la parte demandada coincide con el sabor del alimento correspondiente a la parte demandante de forma tal que se dé una violación de los derechos de autor? A tal efecto, ¿resulta (también) determinante el hecho de que las impresiones de conjunto de ambos sabores sean similares?

\section{MarCo JURÍDICO INTERNACIONAL}

Desde una perspectiva internacional, el Convenio de Berna para la Protección de las Obras Literarias y Artísticas (Acta de París de 24 de julio de 1971) ${ }^{6}$, establece en su artículo 2, apartado 1, que bajo el término "obras literarias y artísticas" se comprenden todas las producciones en el campo literario, científico y

6 En su versión resultante de la modificación de 28 de septiembre de 1979 (en lo sucesivo, "Convenio de Berna”).

AZUAJE PIRELA, Michelle. ¿Puede el sabor de un alimento ser considerado una obra protegida por el derecho de autor? Comentario de la sentencia $n^{\circ}$ c 310/17 del Tribunal de Justicia de la Unión Europea, gran sala, 13 de noviembre de 2018. Revista Justicia y Derecho, Santiago, v. 1, n 1, 2018 
artístico, cualquiera que sea el modo o forma de expresión, tales como los libros, folletos y otros escritos; las conferencias, alocuciones, sermones y otras obras de la misma naturaleza; las obras dramáticas o dramático-musicales; las obras coreográficas y las pantomimas; las composiciones musicales con o sin letra; las obras cinematográficas, a las cuales se asimilan las obras expresadas por procedimiento análogo a la cinematografía; las obras de dibujo, pintura, arquitectura, escultura, grabado, litografía; las obras fotográficas a las cuales se asimilan las expresadas por procedimiento análogo a la fotografía; las obras de artes aplicadas; las ilustraciones, mapas, planos, croquis y obras plásticas relativos a la geografía, a la topografía, a la arquitectura o a las ciencias.

Por su parte, en el apartado 2 del mismo Convenio se reserva a las legislaciones de los países de la Unión la facultad de establecer que las obras literarias y artísticas o algunos de sus géneros no estarán protegidos mientras no hayan sido fijados en un soporte material. Asimismo, conforme al artículo 9, apartado 1 ejusdem, los autores de obras literarias y artísticas protegidas por él gozarán del derecho exclusivo de autorizar la reproducción de sus obras por cualquier procedimiento y bajo cualquier forma.

El marco internacional se complementa con disposiciones como la contenida en el artículo 9 del Acuerdo sobre los Aspectos de los Derechos de Propiedad Intelectual relacionados con el Comercio ${ }^{7}$, que dispone que: los Miembros observarán los artículos 1 a 21 del Convenio de Berna y el Apéndice de este, y también que la protección del derecho de autor abarcará las expresiones, pero no las ideas, procedimientos, métodos de operación o conceptos matemáticos en sí.

Asimismo, el Tratado de la Organización Mundial de la Propiedad Intelectual sobre Derecho de Autor ${ }^{8}$, en su artículo I, apartado 4, reitera que las Partes Contratantes darán cumplimiento a lo dispuesto en los Artículos 1 a 21 y en el Anexo del Convenio de Berna. Y, en los mismos términos señalados anteriormente que la protección del derecho de autor abarcará las expresiones, pero no las ideas, procedimientos, métodos de operación o conceptos matemáticos en sí.

Por su parte, en el Derecho de la Unión la Directiva 2001/29/CE9 es la que regula la protección jurídica de los derechos de autor y otros derechos afines a los derechos de autor en el mercado interior, con particular atención a la sociedad de la información. No obstante, en ella no se define lo que ha de entenderse por "obra"; si bien, en su artículo primero inciso segundo se establece que salvo casos excepcionales ${ }^{10}$, dejará intactas y no afectará en modo alguno las disposiciones del Derecho de la Unión vigentes relacionadas entre otros aspectos con los derechos de autor y derechos afines a los derechos de autor aplicables a la radiodifusión de programas vía satélite y la retransmisión por cable; la duración de la protección de los derechos de autor y determinados derechos afines a los derechos de autor; y la protección jurídica de las bases de datos.

Finalmente, este marco internacional debe ser entendido en sus dimensiones, sin que puedan perderse de vista las disposiciones que resulten aplicables desde la perspectiva de los Estados Miembros.

7 Anexo 1 C del Acuerdo por el que se establece la Organización Mundial del Comercio, firmado en Marrakech el 15 de abril de 1994 y aprobado mediante la Decisión 94/800/CE del Consejo, de 22 de diciembre de 1994, relativa a la celebración en nombre de la Comunidad Europea.

8 de 16 de marzo de 2000 (DO 2000, L 89, p. 6; en lo sucesivo, "Tratado de la OMPI sobre Derecho de Autor", aprobado en nombre de la Comunidad Europea mediante la Decisión 2000/278/CE del Consejo.

9 del Parlamento Europeo y del Consejo, de 22 de mayo de 2001, relativa a la armonización de determinados aspectos de los derechos de autor y derechos afines a los derechos de autor en la sociedad de la información.

10 mencionados en el artículo 11.

AZUAJE PIRELA, Michelle. ¿Puede el sabor de un alimento ser considerado una obra protegida por el derecho de autor? Comentario de la sentencia $n^{\circ}$ c 310/17 del Tribunal de Justicia de la Unión Europea, gran sala, 13 de noviembre de 2018. Revista Justicia y Derecho, Santiago, v. 1, n 1, 2018 


\section{Marco jurídico nacional}

El artículo 1 de la Auteurswet ${ }^{11}$ (Ley sobre el Derecho de Autor neerlandesa) dispone que el derecho de autor es el derecho exclusivo del autor de una obra literaria, científica o artística, o de sus causahabientes, a publicar dicha obra y a reproducirla, sin perjuicio de las limitaciones establecidas en la ley. Asimismo, el artículo 10, apartado 1, de la Ley sobre el Derecho de Autor señala que a sus efectos se entenderá por obras literarias, científicas o artísticas:

1) libros, folletos, periódicos, revistas y cualesquiera otros escritos;

2) obras dramáticas o dramático-musicales;

3) conferencias y alocuciones;

4) obras coreográficas y pantomimas;

5) composiciones musicales con y sin letra;

6) obras de dibujo, pintura, arquitectura, escultura, litografía, grabado y otras obras sobre placa de metal;

7) mapas;

8) planos, croquis y obras plásticas relativos a la arquitectura, a la geografía, a la topografía o a otras ciencias;

9) obras fotográficas;

10) obras cinematográficas;

11) obras de artes aplicadas y dibujos y modelos industriales;

12) programas de ordenador y su material preparatorio,

y, en general, todas las producciones en el campo literario, científico o artístico, cualquiera que sea el modo o la forma de expresión.

De lo dicho se sigue que, de forma similar a diversas legislaciones de derecho de autor, la ley de derecho de autor de los Países Bajos no recoge una lista exhaustiva de materias susceptibles de protección quedando la puerta abierta para que obras no indicadas en ella puedan ser eventualmente protegidas.

\section{5. ¿Puede entonces el sabor de un alimento ser considerado una obra protegida por el Derecho de Autor? ¿Qué resolvió el Tribunal de Justicia de la Unión EUROPEA?}

Para responder a la pregunta de si la Directiva 2001/29/CE se opone a que el sabor de un alimento quede protegido por el derecho de autor, precisó el Tribunal que además de no definir lo que debe entenderse por "obra", la Directiva no contiene ninguna remisión expresa al Derecho de los Estados miembros para determinar el sentido y alcance del concepto de "obra". Por ello concluye que, en virtud de las exigencias tanto de aplicación uniforme del Derecho de la Unión como del principio de igualdad, este

11 Traducida por Van Eechoud (2012).

AZUAJE PIRELA, Michelle. ¿Puede el sabor de un alimento ser considerado una obra protegida por el derecho de autor? Comentario de la sentencia n c 310/17 del Tribunal de Justicia de la Unión Europea, gran sala, 13 de noviembre de 2018. Revista Justicia y Derecho, Santiago, v. 1, n 1, 2018 
concepto debe ser objeto normalmente de una interpretación autónoma y uniforme en toda la Unión. ${ }^{12}$

En ese sentido, para el Tribunal el sabor de un alimento solo podría ser protegido por el derecho de autor con arreglo a la Directiva 2001/29/CE cuando tal sabor pueda calificarse de "obra" en los términos expresados en ella. De ahí que deba precisarse: ¿Qué requiere una producción intelectual para ser considerada "obra" en el Derecho de la Unión Europea?

En términos expresados por el Tribunal es necesario que concurran simultáneamente dos requisitos. En primer lugar, que el objeto en cuestión sea original, en el sentido de constituir una creación intelectual propia de su autor y, en segundo lugar, en el marco de la Directiva, la calificación como "obra", se reserva a los elementos que expresan dicha creación intelectual.

A este respecto se aclara también que, aunque la Unión Europea no es parte contratante del Convenio de Berna, está obligada (porque así lo establece el artículo 1, apartado 4, del Tratado de la OMPI sobre Derecho de Autor, Tratado del cual sí es parte y que la Directiva 2001/29/CE pretende aplicar) a dar cumplimiento a los artículos 1 a 21 del referido Convenio. ${ }^{13}$

En ese sentido, el artículo 2, apartado 1, del Convenio de Berna, establece que las obras literarias y artísticas comprenden todas las producciones en el campo literario, científico y artístico, cualquiera que sea el modo o forma de expresión. Además, de conformidad con el artículo 2 del Tratado de la OMPI sobre el derecho de autor y conforme al artículo 9, apartado 2, del Acuerdo sobre los Aspectos de los Derechos de Propiedad Intelectual relacionados con el Comercio, que también forma parte integrante del ordenamiento jurídico de la Unión, la protección del derecho de autor abarca las expresiones, pero no las ideas, procedimientos, métodos de operación o conceptos matemáticos en sí.

De lo anterior se colige que, el concepto de "obra" contemplado en la Directiva 2001/29/CE implica necesariamente una expresión del objeto de la protección del derecho de autor que la identifique con suficiente precisión y objetividad, aun cuando esta expresión no sea necesariamente permanente. El problema mayor en este caso no sería tanto la durabilidad del sabor como su forma de expresión, y, la precisión y objetividad para identificarlo por el componente de subjetividad que se asocia a ello. Esto es así porque los organismos encargados de la protección de estos derechos y también los particulares o agentes económicos, deben estar en condiciones de conocer con claridad y precisión los objetos protegidos. ¿Cómo podría conocerse con claridad y precisión un sabor?

Para el Tribunal, no hay posibilidad de identificación precisa y objetiva del sabor de un alimento. Lo que resulta más sencillo, por ejemplo, de una obra literaria, pictórica, cinematográfica o musical, que es una expresión precisa y objetiva. La identificación del sabor de un alimento en cambio se basa en lo esencial en sensaciones y experiencias gustativas, que son subjetivas y variables, toda vez que dependen, en particular, de factores relacionados con la persona que prueba el producto en cuestión, como su edad, sus preferencias alimentarias y sus hábitos de consumo, y del entorno o del contexto en que tiene lugar la degustación del producto. Esto atentaría sin duda contra la seguridad jurídica. Además, la identificación precisa y objetiva del sabor de un alimento, que permita distinguirlo del sabor de otros productos de igual naturaleza, no es posible mediante los recursos técnicos disponibles en la fase actual del desarrollo científico.

12 El Tribunal se remite a las sentencias de 16 de julio de 2009, Infopaq International, C5/08, EU:C:2009:465, apartados 27 y 28, y de 3 de septiembre de 2014, D. y Vrijheidsfonds, C201/13, EU:C:2014:2132, apartados 14 y 15.

13 Véanse, en este sentido, las sentencias de 9 de febrero de 2012, Luksan, C277/10, EU:C:2012:65, apartado 59 , y de 26 de abril de 2012, DR y TV2 Danmark, C510/10, EU:C:2012:244, apartado 29.

AZUAJE PIRELA, Michelle. ¿Puede el sabor de un alimento ser considerado una obra protegida por el derecho de autor? Comentario de la sentencia n c 310/17 del Tribunal de Justicia de la Unión Europea, gran sala, 13 de noviembre de 2018. Revista Justicia y Derecho, Santiago, v. 1, n 1, 2018 
Por todo lo anterior, concluyó el Tribunal que el sabor de un alimento no puede ser calificado como "obra" en el sentido de la Directiva 2001/29/CE. Una interpretación contraria derivada de una normativa nacional, es decir, una interpretación en la que se colija que es posible conceder la protección del derecho de autor al sabor de un alimento, se opondría al sentido de la Directiva 2001/29/CE. De esta forma, al no poder considerarse el sabor de un alimento como una obra, consideró innecesario pronunciarse sobre el resto de las cuestiones planteadas por el tribunal remitente.

\section{Consideraciones finales}

El derecho de autor alude a un conjunto de derechos o facultades subjetivas del autor sobre sus creaciones que presentan individualidad, que resulten de su actividad intelectual. Habitualmente las obras son enunciadas como literarias, musicales, teatrales, artísticas, científicas y audiovisuales. Así que, para que nazcan derechos de autor, deben existir un sujeto, "el autor", y un objeto, "la obra."

Pero no cualquier creación puede ser considerada obra y en consecuencia objeto de protección de la propiedad intelectual, para serlo deben contar con al menos dos elementos: la originalidad, esto es, que sea una individualidad, una creación con la impronta de su autor, un aporte creativo propio; y además ese aporte debe a su vez ser susceptible de reproducción o divulgación.

En el marco del Convenio de Berna, se establece entre otras cosas que la protección de las obras no debe estar condicionada al cumplimiento de formalidad alguna. Y, asimismo, que ella se reconocerá cualquiera sea la forma de expresión, mérito o destino de estas. De ahí que los autores suelen distinguir entre el corpus misticum y corpus mechanicum, lo que tiene importantes consecuencias jurídicas y prácticas. El corpus misticum es la forma del pensamiento que se exterioriza en una obra sensible y material perfectamente definida. El corpus mecanicum, es el objeto en que se materializa la obra. ${ }^{14}$

Pues bien, en términos similares a los señalados, la sentencia bajo análisis plantea que, para estar en presencia de una obra, el objeto debe ser original, en el sentido de constituir una creación intelectual propia de su autor y, ella debe ser susceptible de expresarse pues lo protegido es la forma concreta en la que tal creación intelectual se expresa. Si existe originalidad y expresión, en principio nada obsta para que exista obra.

Acercando estos conceptos al caso objeto de análisis, para responder si existe obra o no, es necesario cuestionarse: ¿existe originalidad? ¿el sabor en comento es susceptible de reproducción o divulgación? ¿es posible distinguir con respecto al sabor de un alimento un corpus misticum y corpus mechanicum? Teniendo en cuenta la inmaterialidad de la obra ¿podría considerarse que "el sabor de un alimento" es una forma de expresión de ella?

Lo cierto es que existe originalidad en cuanto a que se trata de una creación del intelecto propia del autor en la que ocurrió una combinación de elementos para lograr un determinado sabor que efectivamente puede ser reproducido y expresado en su preparación. Tan es así que fue digna de ser patentada (no obstante, lo patentado fue el procedimiento para su elaboración y no el sabor en sí mismo). En todo caso téngase en cuenta que, aunque la patente y el derecho de autor se refieren a regímenes de protección distintos, nada obsta para que sobre un mismo objeto pueda recaer más de un derecho de propiedad intelectual.

14 Satanowsky (1954), pp. 158-162.

AZUAJE PIRELA, Michelle. ¿Puede el sabor de un alimento ser considerado una obra protegida por el derecho de autor? Comentario de la sentencia n c 310/17 del Tribunal de Justicia de la Unión Europea, gran sala, 13 de noviembre de 2018. Revista Justicia y Derecho, Santiago, v. 1, n 1, 2018 
Entonces ipor qué concluir que no existe obra en términos de la Directiva 2001/29/CE? ¿Constituye una formalidad contraria al Convenio de Berna -al cual se remite la Directiva-, la exigencia de una identificación precisa y objetiva? O, ¿se trata este último de un requisito meramente registral?

La razón está en que de acuerdo con la distinción doctrinaria entre el corpus misticum y el corpus misticum se requerirá que la forma del pensamiento exteriorizado sea perfectamente definida. ¿Cómo definir perfectamente algo tan subjetivo como un sabor?

En esencia, cualquier cosa puede ser objeto de protección siempre y cuando pueda percibirse y sea original. Entonces, en este caso lo cierto es que como confiesa el Tribunal, aunque un sabor (de forma similar a un olor) puede percibirse, su problema no es de originalidad, sino relativo a su identificación precisa y objetiva.

Hará falta entonces en relación con el sabor de un alimento, que existan mecanismos que permitan distinguirlo del sabor de otros productos de igual naturaleza. Lo cual en la actualidad no es posible en virtud de no contar con los recursos técnicos disponibles para ello, siendo esa la verdadera razón por la que se dificulta la protección del sabor. La dificultad no está entonces en que no exista originalidad o forma de expresión artística sino en el hecho de que no existen medios que den certeza del objeto protegido lo que lo convierte en un problema de seguridad jurídica. Lo anterior significa que nada obsta para que en el futuro si es que se encuentran medios técnicos disponibles, sea posible tal reconocimiento y protección.

\section{Bibliografía Citada}

\section{Libros y artículos}

Koelman, Kamiel (2006): “El derecho de autor ante los tribunales: ¿El perfume como expresión artística?", Revista de la OMPI Número 5/2006: pp. 2-3.

SATANOWSky, IsidRo (1954): Derecho Intelectual (Buenos Aires, Tipográfica Editora Argentina). Vol. I.

\section{Legislación y tratados internacionales}

Acuerdo sobre los Aspectos de los Derechos de Propiedad Intelectual relacionados con el Comercio, Anexo 1C del Acuerdo de Marrakech por el que se establece la Organización Mundial del Comercio, firmado en Marrakech, Marruecos, el 15 de abril de 1994.

Auteurswet-Copyright Act, de 23 de septiembre de 1912, (trad. Van Eechoud, Mireille,).

Convenio de Berna para la Protección de las Obras Literarias y Artísticas, Acta de París de 24 de julio de 1971.

Directiva 2001/29/CE del Parlamento Europeo y del Consejo, de 22 de mayo de 2001, relativa a la armonización de determinados aspectos de los derechos de autor y derechos afines a los derechos de autor en la sociedad de la información.

Tratado de Funcionamiento de la Unión Europea. Versión Consolidada. Diario Oficial de la Unión Europea, 30 de marzo de 2010.

AZUAJE PIRELA, Michelle. ¿Puede el sabor de un alimento ser considerado una obra protegida por el derecho de autor? Comentario de la sentencia $n^{\circ}$ c 310/17 del Tribunal de Justicia de la Unión Europea, gran sala, 13 de noviembre de 2018. Revista Justicia y Derecho, Santiago, v. 1, n 1, 2018 
Tratado de la Organización Mundial de la Propiedad Intelectual sobre Derecho de Autor, adoptado en Ginebra el 20 de diciembre de 1996.

\section{Jurisprudencia}

Courdecassation, chambrecommerciale,10dediciembrede2016,No11-19.872ECLI:FR:CCASS:2013:CO01205).

Sentencia del Hoge Raad, de 16 de junio de 2006, caso: Kecofa c./Lancôme (LJN AU8940).

Sentencia del Tribunal de Justicia de la Unión Europea (Sala Cuarta), de 16 de julio de 2009, caso: Infopaq International, C5/08, (EU:C:2009:465).

Sentencia del Tribunal de Justicia de la Unión Europea (Sala Tercera), de 9 de febrero de 2012, caso: Martin Luksan contra Petrus van der Let., C277/10, (EU:C:2012:65).

Sentencia del Tribunal de Justicia de la Unión Europea (Sala Tercera), de 26 de abril de 2012, caso: DR y TV2 Danmark, C510/10, (EU:C:2012:244).

Sentencia del Tribunal de Justicia (Gran Sala), de 3 de septiembre de 2014, caso: Johan Deckmyn y Vrijheidsfonds VZW contra Helena Vandersteen y otros, C201/13, (EU:C:2014:2132). 